$\begin{array}{cc}\text { ACADEMIA ROMÂNĂ } & \text { Rev. Roum. Chim., } \\ \text { Revo, 65(3), 291-303 } \\ \text { Revue Roumaine de Chimie } \\ \text { http://web.icf.ro/rrch/ }\end{array}$

\title{
THE EFFICIENCY OF Fe@Mg-Al LAYERED DOUBLE HYDROXIDE FOR CADMIUM REMOVAL FROM WATER SAMPLES
}

\author{
Rokhsareh MOTALLEBI, Ali MOGHIMI, ${ }^{*}$ Hamidreza SHAHBAZI and Hakim FARAJI \\ Department Of Chemistry, Varamin Branch, Islamic Azad Uneversity,Varamin, Iran
}

Received January 25, 2020

\begin{abstract}
The fast development of the population and industrialization cause many environmental problems due to the increase of carcinogenic compounds and heavy metals in the environment. In this regard, many studies have been conducted to remove these compounds from the water, air, and soil. The Layered double hydroxide is one of the adsorbents which have attracted great attention in recent years owing to its ease of preparation, costeffectiveness, environmental compatibility, and non-toxicity. Consequently, in this study, magnetic nanoparticles of Fe@MgAl layered double hydroxide have been modified with ammonium pyrrolidine dithiocarbamate (APDC) and then used as an adsorbent to form a complex with cadmium ions and removing them. Based on the absorption properties of synthesized magnetic
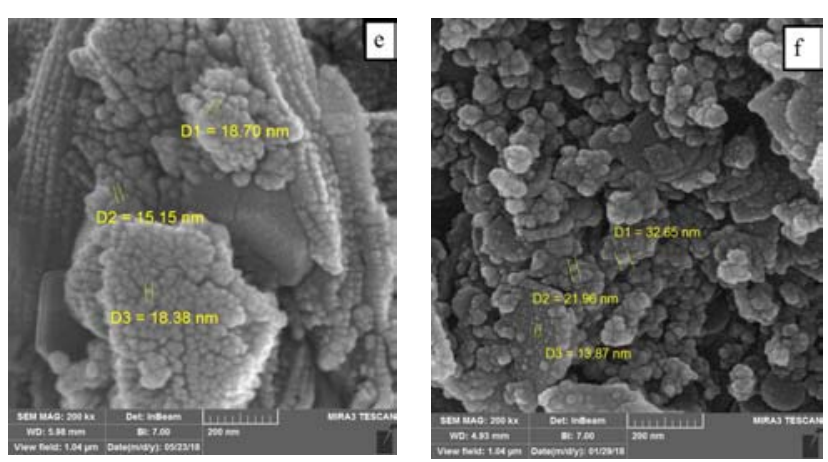

nanoparticles, an easy, practical, economical and repeatable method has been developed to remove contaminants from water, including heavy metal ions. Cadmium ion has been studied by floating in an aqueous medium by these nanoparticles. Also, the optimal values of effective factors such as $\mathrm{pH}$, amount of magnetic nanoparticles, contact time, temperature and sample volume and ligand concentration were $7,0.045 \mathrm{~g}, 30 \mathrm{~min}, 35^{\circ} \mathrm{C}, 25 \mathrm{~mL}$ and $1.7 \mathrm{mg} \mathrm{L}^{-1}$, respectively. The isotherm equations have been also investigated to evaluate the absorption quality. The thermodynamic parameters as well as the effects of interfering ions have been investigated as well. A flame atomic absorption spectrometer (FAAS) has been applied to detect Cd ions.
\end{abstract}

\section{INTRODUCTION}

In recent decades, dual-layer hydroxides (LDH) have been used as inexpensive, environmentally friendly and practical adsorbents for the absorption of various contaminants. LDHs are octahedral positively charged brucite-like sheets with anion or oxyanion and water molecules in interlayer spaces. ${ }^{1}$ The structure of LDHs is similar to the hydrotalcite-like compounds. ${ }^{2}$ Two important properties of LDHs are high specificity and anion exchange capacity (3meq $/ \mathrm{g}$ ). These properties allow LDHs to absorb all types of anionic and polar molecules. ${ }^{3}$ Javad et al. (2017) investigated LDH-based Fe- MoS which is a very practical absorbent for selected heavy metals like $\mathrm{Pb}^{2+}, \mathrm{Ag}^{2+}, \mathrm{Hg}^{2+}$ and $\mathrm{Cu}^{2+} \cdot{ }^{4} \mathrm{Yu}$ and colab. (2019) synthesized an CNF/LDH absorbent by which they investigated the elimination of the heavy metals like $\mathrm{Cu}$ (II) and $\mathrm{Cr}(\mathrm{VI})$ from aquatic environments. ${ }^{5}$

One of the most important application of superparamagnetic nanoparticles refers to magnetic extraction of solid phase. In this method, magnetic nanoparticles are used as solid phase. Compared to the traditional approaches which used particles in solid phase extraction, magnetic nanoparticles have a significant high surface-to-volume ratio which provides high extraction capacity and efficiency. Other advantages of magnetic nanoparticles refers to the simple surface modification as well as possibility of selective extraction. Furthermore, the

\footnotetext{
*Corresponding author: alimoghimi@iauvaramin.ac.ir; kamran9537@yahoo.com; Tel.: 09122130124
} 
magnetic particles can be simply adsorbed by using an external magnetic field considered a very useful property for extraction. As it does not need to be separated by tedious centrifugation or filtration procedures, this is considered as an important reason for using magnetic nanoparticles as an adsorbent. ${ }^{6}$

Ammonium pyrrolidine dithiocarbamate is usually used as a complexing agent to remove metal ions from aqueous samples. One of the most important applications of this compound refers to the usage of APDC for measuring metal ions through atomic absorption. ${ }^{7}$ This ligand is applied in the photometric field too. Ammonium-1-pyrrolidine dithiocarbamate has special properties due to its stability in media with different $\mathrm{pH}$ values. This feature can increase the adsorption selectivity by adjusting $\mathrm{pH}$. However, the problem of simultaneous measurement of metal ions largely exists. ${ }^{8}$

Metals are determined by various methods such as calorimetry, polarography and atomic absorption methods. The atomic absorption method is usually used in the concentration range from microgram to 10 milligrams in a liter. In the atomic absorption method, initial purification and cleanup must be performed prior to the measurement of different sample solutions including particles, organic materials, metals with organic-inorganic bands, and soluble and suspended metals. Samples without color, transparent and with low turbidity $(\mathrm{TU}<1)$ can be directly measured. ${ }^{9}$ Since the samples used in this study had a good transparency, there any need for pre-purification.

Cadmium is found in the earth's crust and is usually found in combination with zinc. In industry, it is an inevitable by-product of zinc and copper extraction. Cadmium can transfer to the environment through the application of fertilizers and pesticides. Cadmium can mainly enter the human body through various foods. These include liver, mushrooms, oyster, cocoa powder, and seaweed. Smoking cigarette is also expected to increase the amount of cadmium in the human body. Tobacco smoke enters the cadmium into the body and is transmitted by the blood to various parts of the body which leads to the side-effects enhancements. Cadmium inhalation can cause severe lung damage or even death. Other adverse effects caused by cadmium in the human body include diarrhea, abdominal pain, hyper vomiting, bone fracture, infertility, cancer, and

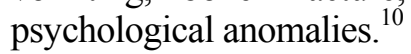

In the current investigation, the researchers tried to remove cadmium ions from aqueous samples with magnetic nanoparticle modified by the APDC ligand. To measure cadmium, the appropriate conditions were investigated to achieve the goal and the effective factors were optimized too. The reversibility or irreversibility and the quality of absorption have been studied too.

\section{EXPERIMENTAL}

\section{Reagents and materials}

Ferric chloride hexahydrate $\left(\mathrm{FeCl}_{3} \cdot 6 \mathrm{H}_{2} \mathrm{O}\right)$ and Hydrazine hydrate $\left(\mathrm{N}_{2} \mathrm{H}_{4} \cdot \mathrm{H}_{2} \mathrm{O}\right)(64-65 \%)$ were obtained from Sigma Aldrich Ltd. (St Louis, USA). It should be added that, magnesium nitrate hexahydrate $\left(\mathrm{Mg}\left(\mathrm{NO}_{3}\right)_{2} \cdot 6 \mathrm{H}_{2} \mathrm{O}\right)$, aluminum nitrate nonahydrate $\left(\mathrm{Al}\left(\mathrm{NO}_{3}\right) \cdot 3 \cdot 9 \mathrm{H}_{2} \mathrm{O}\right), \mathrm{NaOH}$, hydrochloric acid ( $\mathrm{HCl} 37 \%$ ), and $\mathrm{CdCl}_{2} \cdot \mathrm{H}_{2} \mathrm{O}$ were purchased from Merck Chemicals (Darmstadt, Germany). Powder of ammonium pyrrolidine dithiocarbamate (APDC) was obtained from fisher scientific co.

\section{Instrumentation}

A PG-990 atomic absorption spectrometer has been used to determine the concentration of cadmium ion in the solution after and before adsorption experiments. A magnet with field strengths of 2 Tesla was used to isolate the magnetic adsorbent from the sample during the optimization process. An autoclave, vacuum oven, and an ultrasonic probe were applied for the synthesis of magnetic nanoparticles. An incubator shaker with refrigerator was used for optimization.

\section{Characterization}

In order to the functional groups, the FTIR test was performed using a Perkin Elmer spectrometer (Spectrum two model). In order to investigate the morphology of the synthesized magnetic nanoparticles, a TESCAN MIRA 3 field emission-scanning electron microscope (Czech Republic) equiped with an energy dispersive spectrometer (EDS, SAMx, France), and the IDFix software was used. The crystalline structures of the samples were analyzed by using X-ray diffraction (XRD, X'Pert PRO, PANalytical) with $\mathrm{Cu} \mathrm{K \alpha}$ radiation $(\lambda=1.5418 \AA)$. Measuring the magnetic properties of the synthesized nanoparticles was done in a vibrating sample magnetometer (VSM/AGFM Meghnatis Daghigh Kavir Co., Kashan, Iran) and at the room temperature of an applied magnetic field sweeping between $-10,000$ Oe and $+10,000$ Oe.

\section{Synthesis of Fe@Al-Mg LDH}

The synthesis of adsorbent was performed according to the method previously reported by Zhou. ${ }^{1}$ First, $2.4 \mathrm{~g}$ of $\mathrm{FeCl}_{3} \cdot 6 \mathrm{H}_{2} \mathrm{O}$ was added to $12 \mathrm{~mL}$ of ethanol. Then, $3 \mathrm{~g}$ of $\mathrm{NaOH}$ and $6 \mathrm{ml}$ of hydrazine hydrate were added to the mixture and the resultant solution was placed on the stirrer. After the mixing process, the sample solution was added on the autoclave at $200{ }^{\circ} \mathrm{C}$ for 2 hours and 30 minutes. Then, it was allowed to be cooled to the room temperature. This step was performed, one extra time. The obtained black product was washed several times by with deionized water and dried to $50{ }^{\circ} \mathrm{C}$ in the vacuum oven. In the next step, $0.3 \mathrm{~g}$ of the dried sample that was obtained in the previous step was dispersed into $45 \mathrm{~mL}$ of ethanol and homogenized for $20 \mathrm{~min}$ with an ultrasonic probe. After that, $0.96 \mathrm{~g}$ of $\mathrm{Mg}\left(\mathrm{NO}_{3}\right)_{2}$. $6 \mathrm{H}_{2}$ Oand $0.46 \mathrm{~g}$ of $\mathrm{Al}\left(\mathrm{NO}_{3}\right)_{3} .9 \mathrm{H}_{2} \mathrm{O}$ were added to the resulting mixture and the suspension was placed on a stirrer for one hour. During this time, the $\mathrm{pH}$ of the solution was controlled at 11 . Finally, the resulting precipitate was washed until being neutral and dried at $50{ }^{\circ} \mathrm{C}$ in the vacuum oven (Fig. 1). 


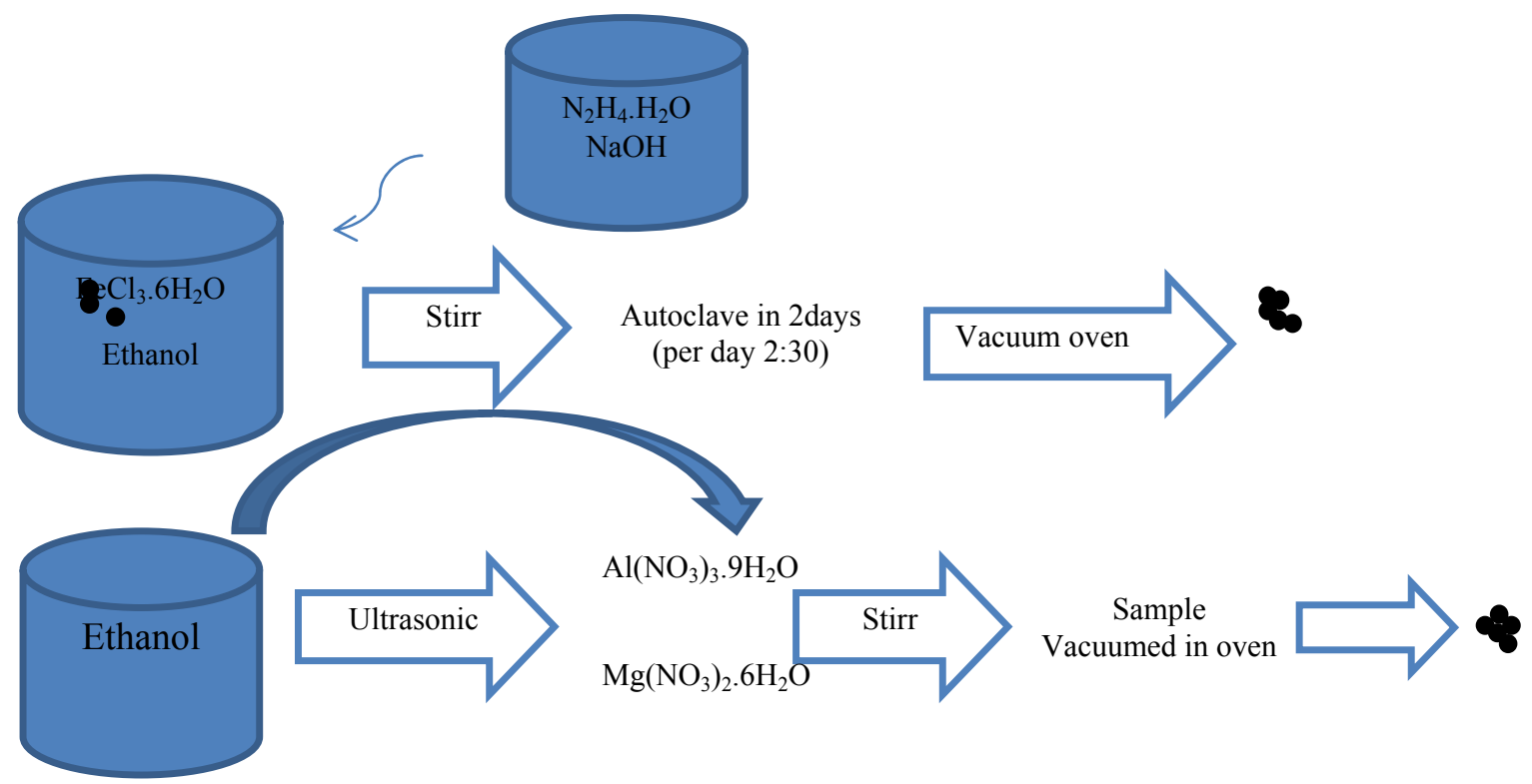

Fig. 1 - Scheme of Fe@Mg-Al LDH synthesis steps.

\section{RESULTS AND DISCUSSION}

\section{Characterization of Fe@Mg-Al LDH}

In Fig. 2 (a) and 2 (b) and 2 (i) FTIR test of the adsorbent is shown. The wave numbers were from 3409.40 to $3411.93\left(\mathrm{~cm}^{-1}\right)$ which were associated with the tensile vibration of $\mathrm{OH}^{-}$. The 1615.93 and $1619.31\left(\mathrm{~cm}^{-1}\right)$ wave numbers can be assigned to the vibrations of hydroxyl groups. The increase of bands intensity is caused due to the bonds between the $\mathrm{OH}$ and COO-groups. The wave numbers range between 500 and $800 \mathrm{~cm}^{-1}$ are related to the chemical bond between the oxygen and $\mathrm{Al}, \mathrm{Mg}$ or Fe. The shift of band from 1615.93 to $1619.31\left(\mathrm{~cm}^{-1}\right)$ in the spectrum is related to effect of cadmium adsorption that shows cadmium uptake on LDH adsorbent.

The XRD patterns of $\mathrm{Fe}$ and the final nanocomposite (Fe@MgAl LDH) are shown in Fig. 2c and Fig. $2 \mathrm{~d}$ respectively. In the Fig. $2 \mathrm{c}$, the peak located at $2 \theta=32$ which is shown at $2 \theta=29.5$ in Fig. 2d. Additionally, the peak is located at $2 \theta=45$ in Fig. $2 \mathrm{c}$ as shown in Fig. $2 \mathrm{~d}$ at $2 \theta=48$ with a lower intensity. The typical peaks at $2 \theta=11,32,39$, and 48 are ascribed to the LDH (according ASTM D5357 - 19). Figures 2e and 2f shows the FESEM images of $\mathrm{Fe}$ and $\mathrm{Fe} @ \mathrm{MgAl} \mathrm{LDH}$, respectively. As it is shown, the average size of Fe nanoparticles was increased after its modification with LDH which confirm the successful synthesis of the $\mathrm{Fe} @ \mathrm{MgAl}$ LDH nanocomposite. This distances among the iron particles which could be find in the first step of absorbant (2e)synthesis were filled by LDH in the second step of synthesis(2f) (in figure $2 e, D_{1}, D_{2}$ and
$\mathrm{D}_{3}$ are equal to $18.7,15.15,18.38$ and figure $2 \mathrm{f}, \mathrm{D}_{1}$, $\mathrm{D}_{2}$ and $\mathrm{D}_{3}$ are equal to $32.65,21.96$ and 13.87). Magnetic properties of the synthesized adsorbent at room temperature were characterized by using the VSM. Fig. $2 \mathrm{~g}$ and Fig. $2 \mathrm{~h}$ relates to the VSM test. In a VSM curve, the vertical axis refers to the saturation magnetization (Ms) and the horizontal axis refers to the magnetic field. The amount of saturation magnetization in iron nanoparticles and $\mathrm{Fe} @ \mathrm{Mg}-\mathrm{Al} \mathrm{LDH}$ nanocomposite was 6.5 and 2.5 emu $\mathrm{g}^{-1}$, respectively. It is obvious that the saturation magnetization of $\mathrm{Fe} @ \mathrm{Mg}-\mathrm{Al}$ LDH was lower than bare $\mathrm{Fe}$, which might relate to the $\mathrm{Fe}$ nanoparticles coating with a magnetically inactive hydroxide layer.

\section{Optimization of the removal process}

The adsorption efficiency in the optimization stages was determined from (1) and (2) equations:

$$
\% R-\frac{C_{0}-C_{e}}{C_{0}} \times 100
$$

where, $\mathrm{C}_{0}$ is the initial concentration of metal ion in the sample solution $\left(\mathrm{mg} \mathrm{L}^{-1}\right), \mathrm{C}_{\mathrm{e}}$ is the metal ion concentration in the sample solution after finishing the contact time with the adsorbent $\left(\mathrm{mg} \mathrm{L}^{-1}\right), \mathrm{M}$ is the adsorbent mass $(\mathrm{g}), \mathrm{V}$ is the sample solution volume (liter), $\mathrm{q}_{\mathrm{e}}$ is the amount of adsorbent ( $\mathrm{mg} \mathrm{g}^{-1}$ ) and $\mathrm{R} \%$ is the percentage of the adsorption.

$$
q_{e}-\frac{C_{0} C_{e}}{M} \times 100
$$



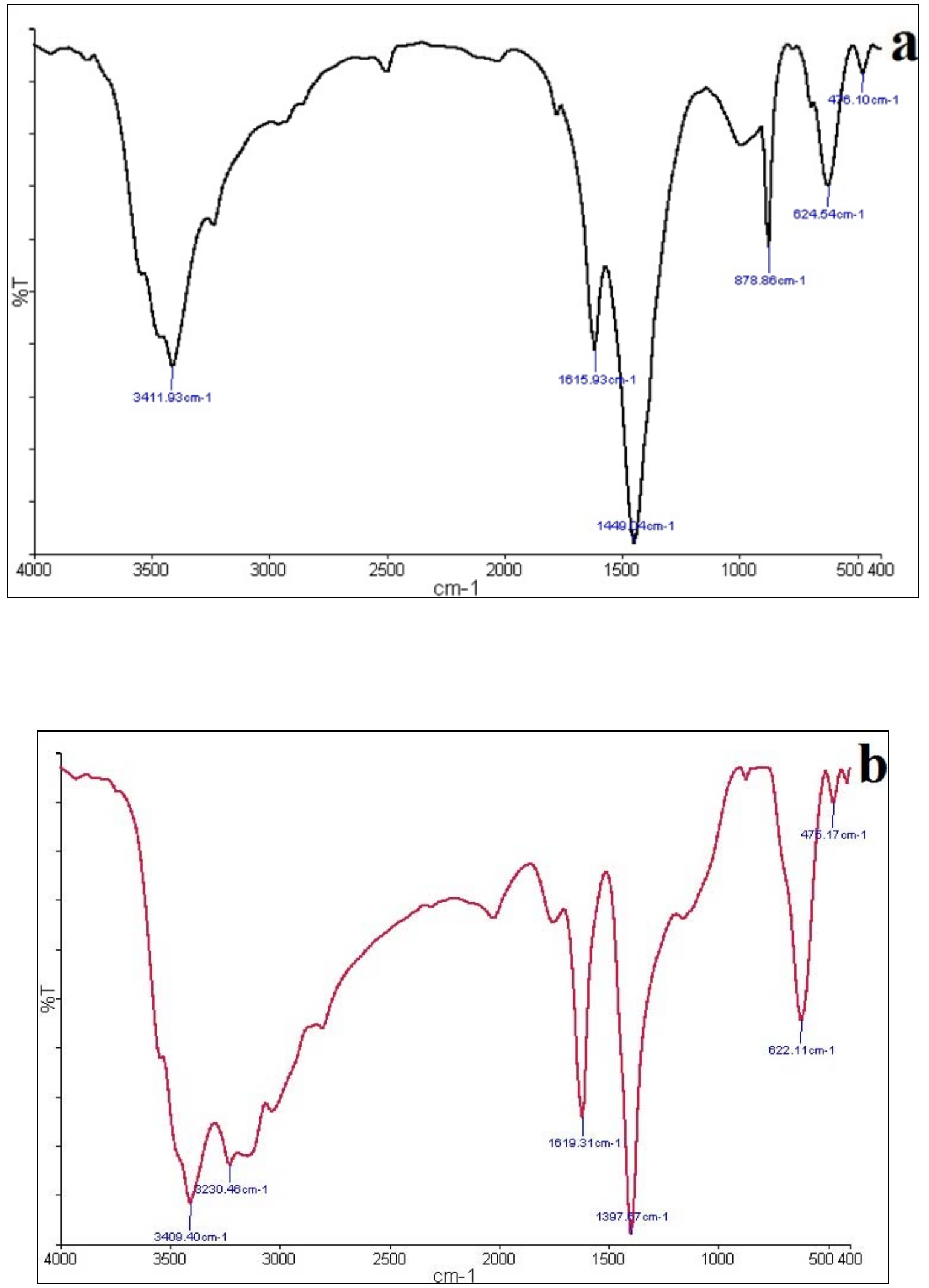

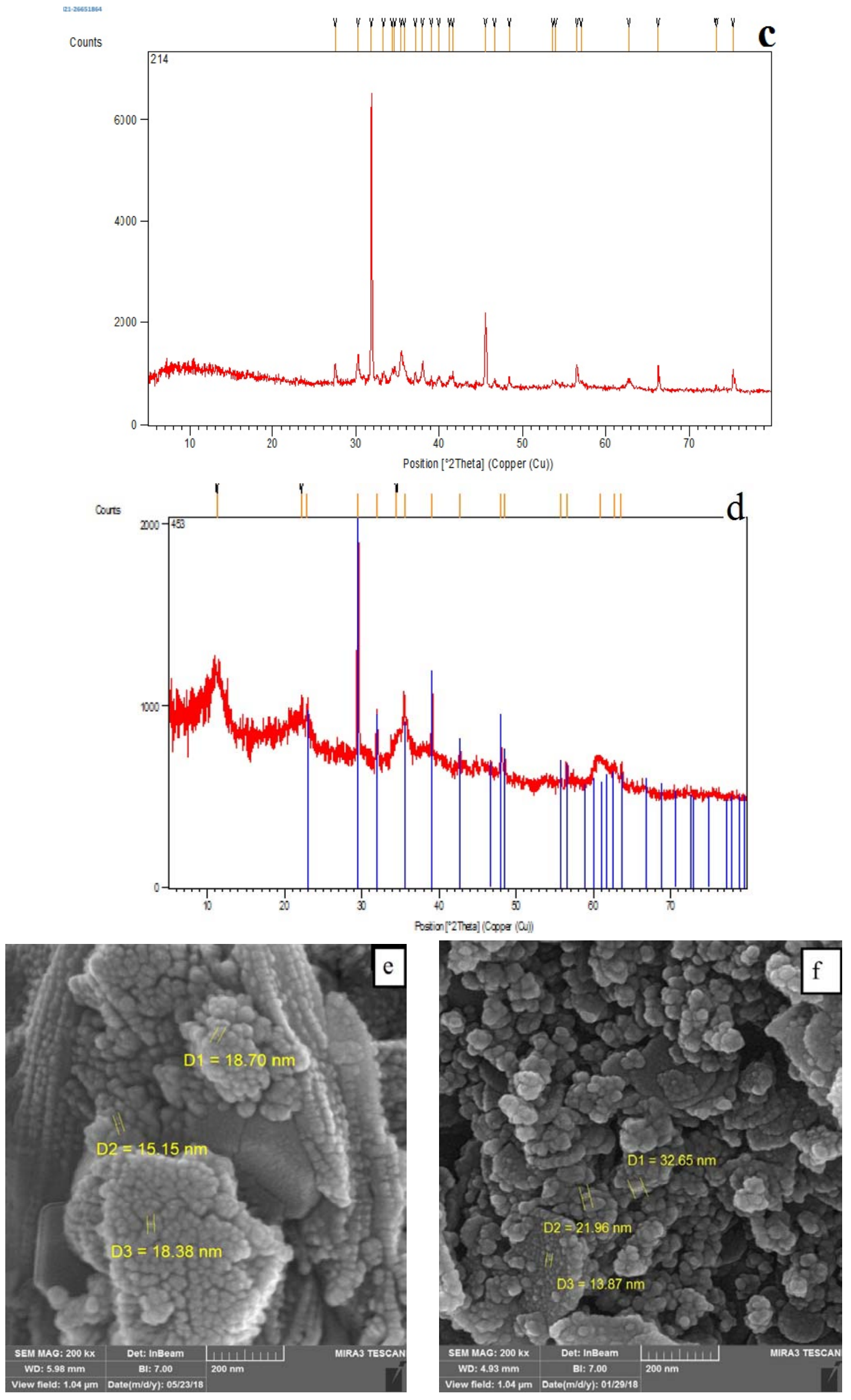


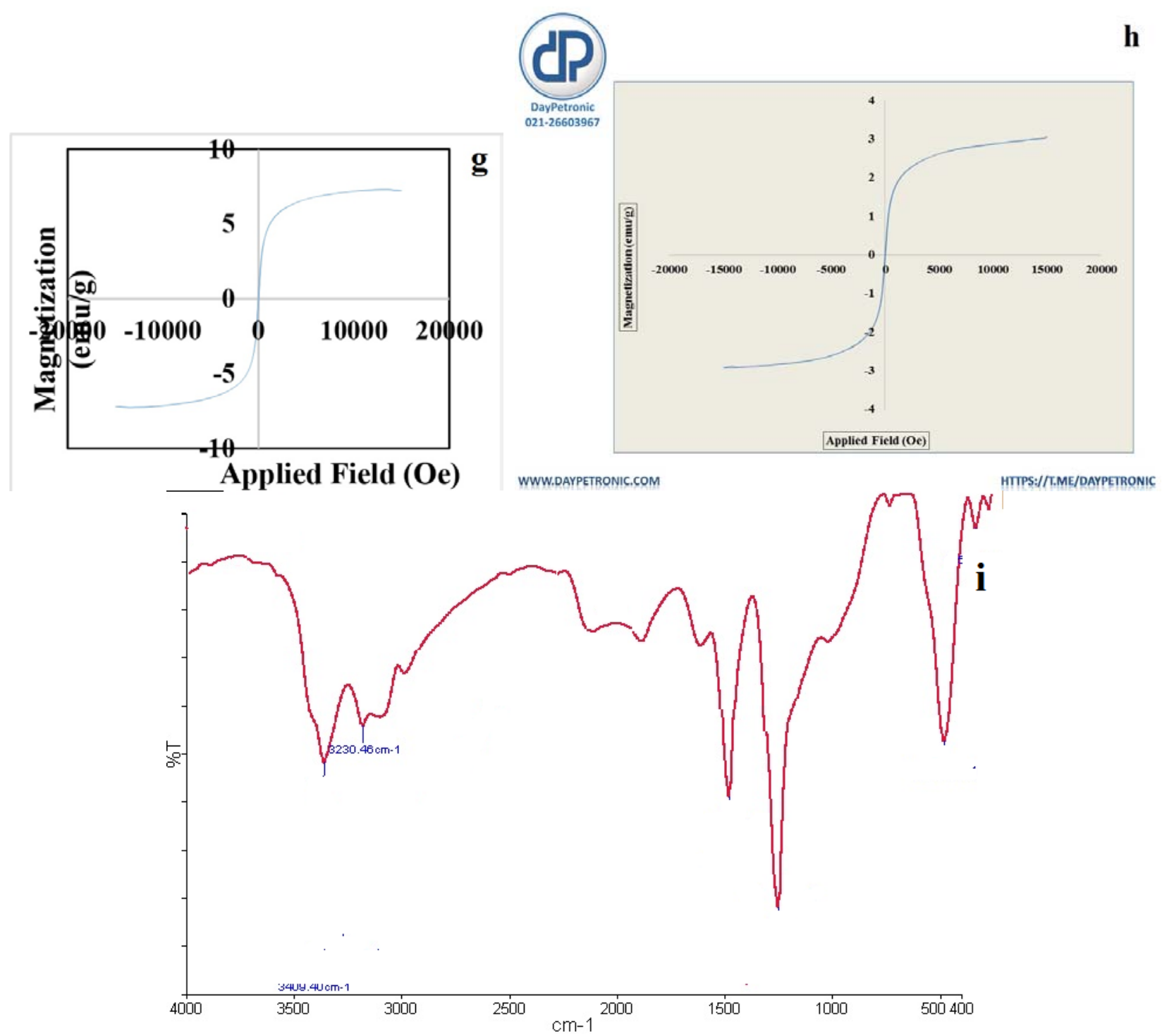

Fig. 2 - Characterization of the adsorbent: (a) FTIR pattern of Fe; (b) FTIR pattern of Fe@Mg-Al LDH; (c) XRD pattern of Fe; (d) XRD pattern of Fe@Mg-Al LDH; (e) SEM image of Fe nanoparticles; (f) SEM image of Fe@Mg-Al LDH; (g) VSM magnetization curve of Fe nanoparticles; and (h) VSM magnetization curve of Fe@Mg-Al LDH (i) FTIR pattern of Fe@Mg-Al LDH-Cd.

\section{Effect of the pH}

$\mathrm{pH}$ is one of the important factors which can affect surface features and surface load in the the extraction and absorption process Thus, firstly, it should be investigated and optimized. To this aim, the same samples with different $\mathrm{pH}$ values ranging from 1 to 8 were prepared. ${ }^{12-13}$ After obtaining the result of the absorption efficiency, the value of 7 was selected as the appropriate $\mathrm{pH}$ to continue the study as it had the highest efficiency. As shown in Fig. 3, by increasing the $\mathrm{pH}$, the adsorption efficiency was increased due to the presence of adsorption sites. The absorption efficiency was then decreased in alkaline $\mathrm{pH}$ due to the formation of insoluble cadmium hydroxide complex ${ }^{14-15}$ (The materials used in the acidic environments is
Hydrochloric acid and for base environment is Sodium hydroxide).

\section{Effect of the adsorbent amount}

First, the same samples containing cadmium ions (3 ppm) and APDC ligand (1.5 ppm) fixed at $\mathrm{pH}$ 7. After adding different amounts of adsorbent to the samples and agitating the sample for $30 \mathrm{~min}$ (by shaker), the adsorbent was separated from the sample solutions and the absorbance was measured. The results are shown in Fig. 4. Since there was no significant difference between 0.045 and $0.05 \mathrm{~g}$ of adsorbent, the amount of $0.045 \mathrm{~g}$ of Fe@Al-Mg LDH with good efficiency was selected to save the adsorbent. 


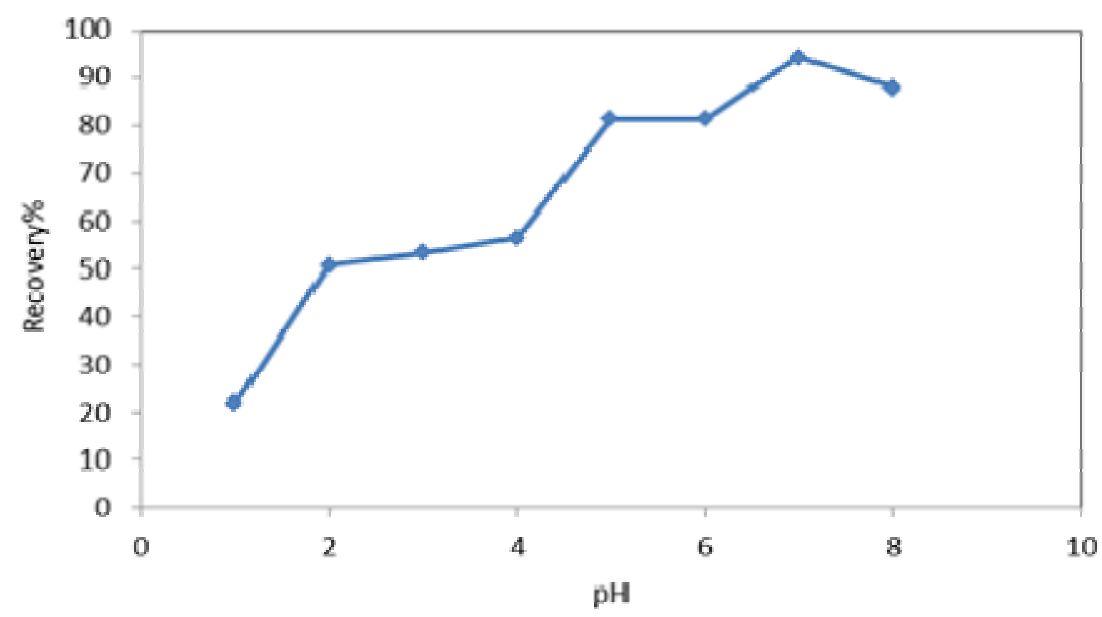

Fig. 3 - Effect of the sample solution $\mathrm{pH}$ on the cadmium adsorption efficiency.

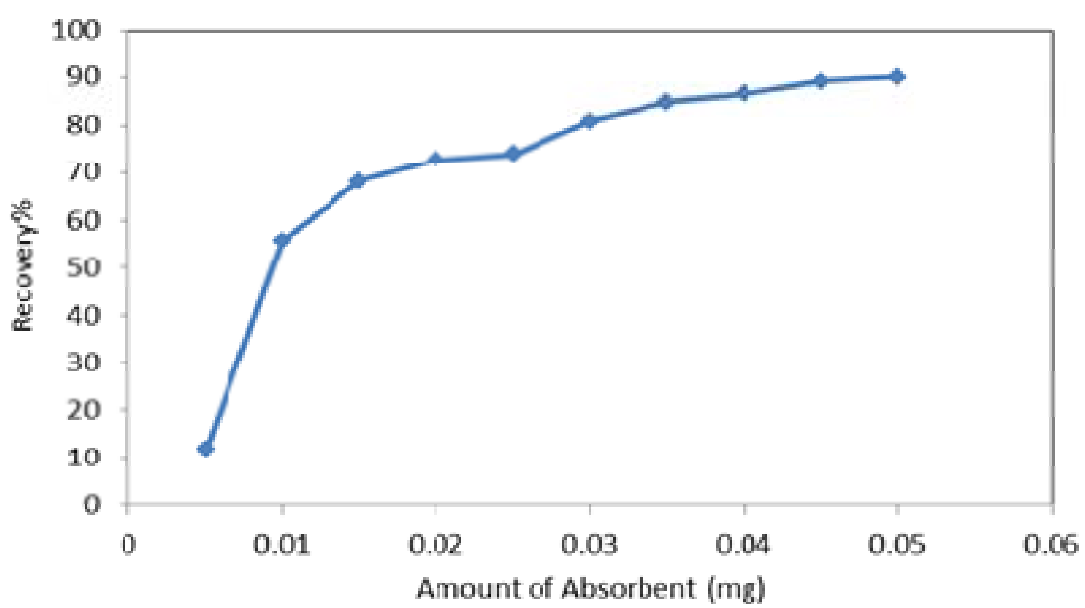

Fig. 4 - Effect of the adsorbent amount on the cadmium adsorption efficiency.

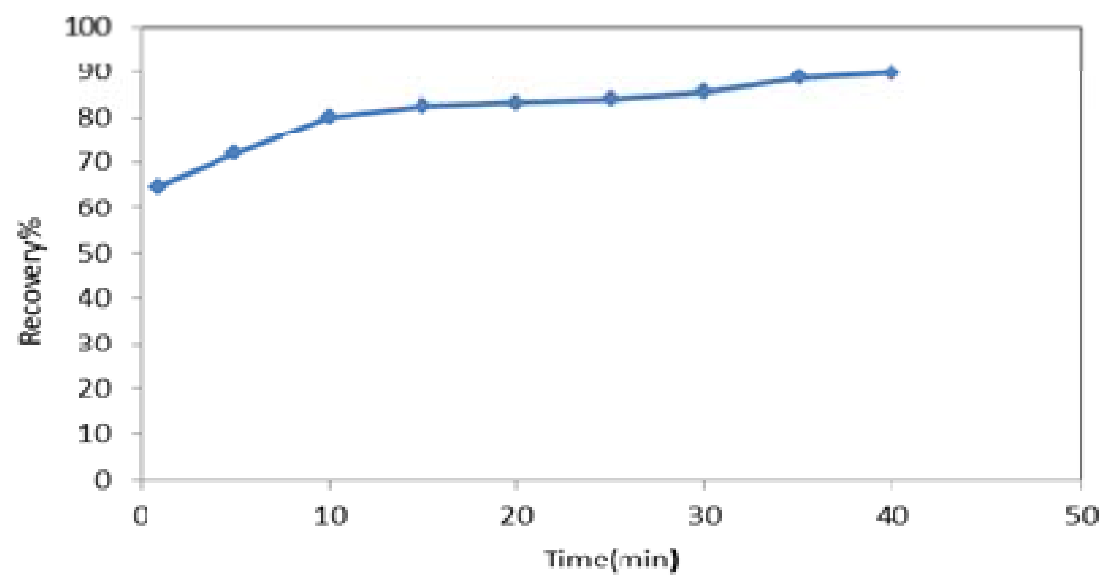

Fig. 5 - Effect of the contact time on the cadmium adsorption efficiency.

\section{Effect of contact time}

One of the other effective factors that determine the absorption efficiency is the contact time between the adsorbent and analytes in the sample solution. At this stage, similar to the previous steps, different samples with a constant concentration of ligand and cadmium ions were prepared and exposed to the optimum amounts of adsorbent for 1 to 40 minutes at the ambient temperature. After investigating the results obtained by the atomic absorption spectrometer, 
the contact time of 35 minutes was chosen, as shown in Fig. 5. At this time the balance between the adsorbent and the $\mathrm{Cd}^{2+}$ ion happened and the adsorption process was completed.

\section{Effect of APDC amount}

Different samples containing APDC ligand with the concentrations of $0.3,0.7,1,1.3,1.7$ and $2 \mathrm{mg} / \mathrm{L}$, and the cadmium ion with the concentration similar to the previous steps were prepared. The $\mathrm{pH}$ of the samples were also fixed at 7, and the experiment was performed in the room temperature and the optimal amount of absorbent and contact time were considered. The results are shown in Fig. 6. As can be seen, by increasing the concentration of the ligand up to $1.7 \mathrm{mg} / \mathrm{L}$ the adsorption efficiency was increased. This happened, due to the formation of the complex between ligand and cadmium ions. The reduction in efficiency at the higher concentration of $2 \mathrm{mg} / \mathrm{L}$ could be happened due to the saturation of the adsorption sites.

\section{Effect of sample volume}

So far, all processes were performed at $25 \mathrm{~mL}$ on the sample. Here, the samples with optimal concentrations of ligand and cadmium ions were prepared in different volumes of $25,50,100,150$ and $200 \mathrm{~mL}$. Optimization was performed at the optimal $\mathrm{pH}$, adsorbent amount, contact time and constant temperature. After measuring the absorbance and calculating the efficiency by drawing the curve, $25 \mathrm{~mL}$ of the sample solution was selected due for the better adsorption efficiency (Fig. 7).

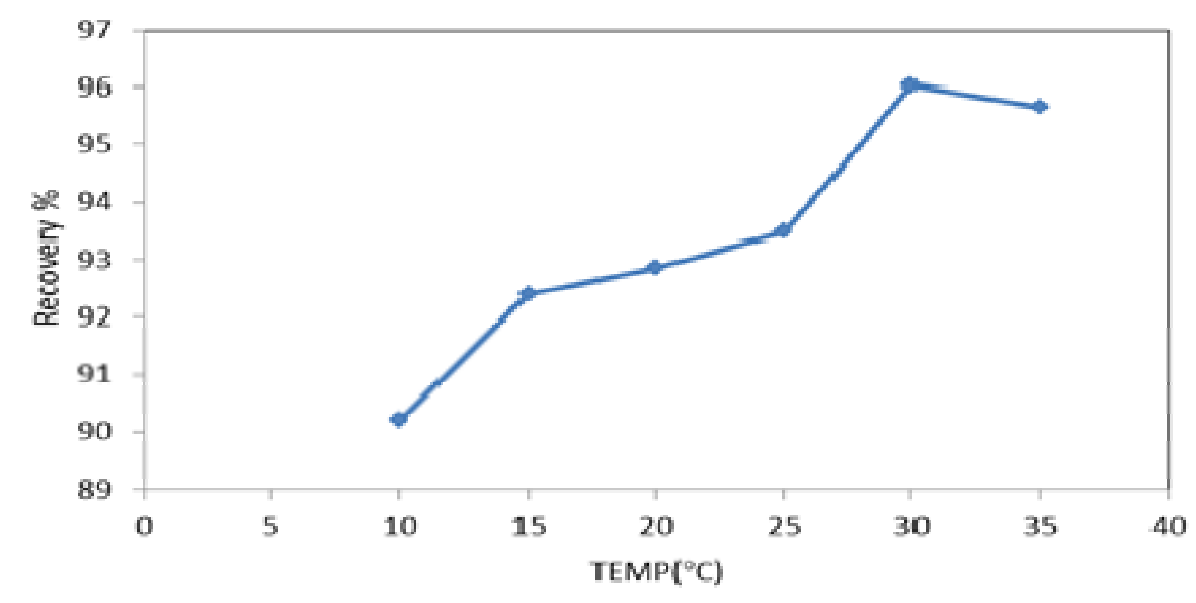

Fig. 6 - Effect of the APDC concentration on the cadmium adsorption efficiency.

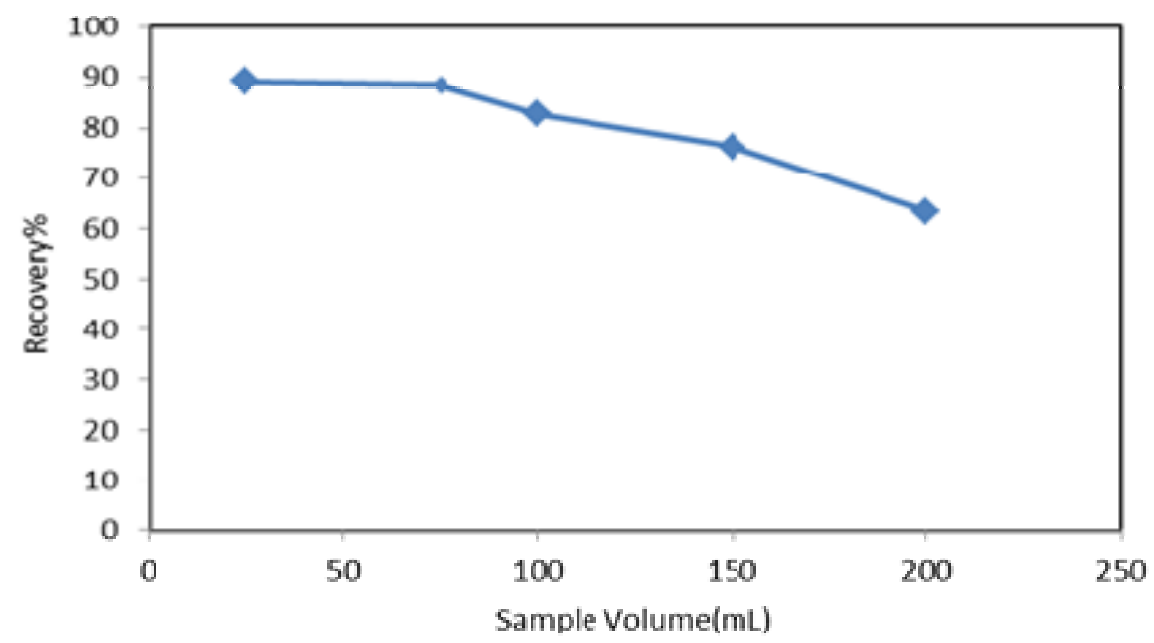

Fig. 7 - Effect of the sample volume on the cadmium adsorption efficiency. 


\section{Effect of temperature}

In order to obtain the appropriate temperature, various samples with the same concentration of ligand and cadmium ion were prepared at $\mathrm{pH} 7$. After adding $0.045 \mathrm{~g}$ of the adsorbent, the samples were placed at shaker incubator which was equipped with the refrigerator at different temperatures $(10,15,20$, 25,30 and $\left.35^{\circ} \mathrm{C}\right) .{ }^{16}$ From the obtained results and calculating the efficiency and drawing the curve as shown in Fig. 8, it can be observed that with increasing the temperature, the adsorption efficiency was also increased. Since there was no difference between $30^{\circ} \mathrm{C}$ and $35^{\circ} \mathrm{C}$, the temperature of $30^{\circ} \mathrm{C}$ was determined as the optimum value.

\section{Effect of interfering ions}

In order to confirm the efficiency of the absorbent, the effect of interfering ions was investigated ${ }^{13-17}$. In order to study interferences, different concentrations of other ions were added to the sample solution containing cadmium ion and ligand while other experimental parameters such as temperature, $\mathrm{pH}$, contact time and adsorbent amount were constant. After separating the analyte from the adsorbent, the concentration of cadmium ions and adsorption efficiency were calculated and the results were shown in Table 1. It is obvious that there was a little difference between the adsorption efficiencies in the presence of interfering ions and their absence. A reason for this is that the absorbent has sufficient active sites and the presence of interfering ions has no significant effect on the removal of cadmium ions(According to the table, the density of annoying ions is $100,1,1,5,1000,50,2,5,200,4$, $1000 \mathrm{mg} / \mathrm{L})$.

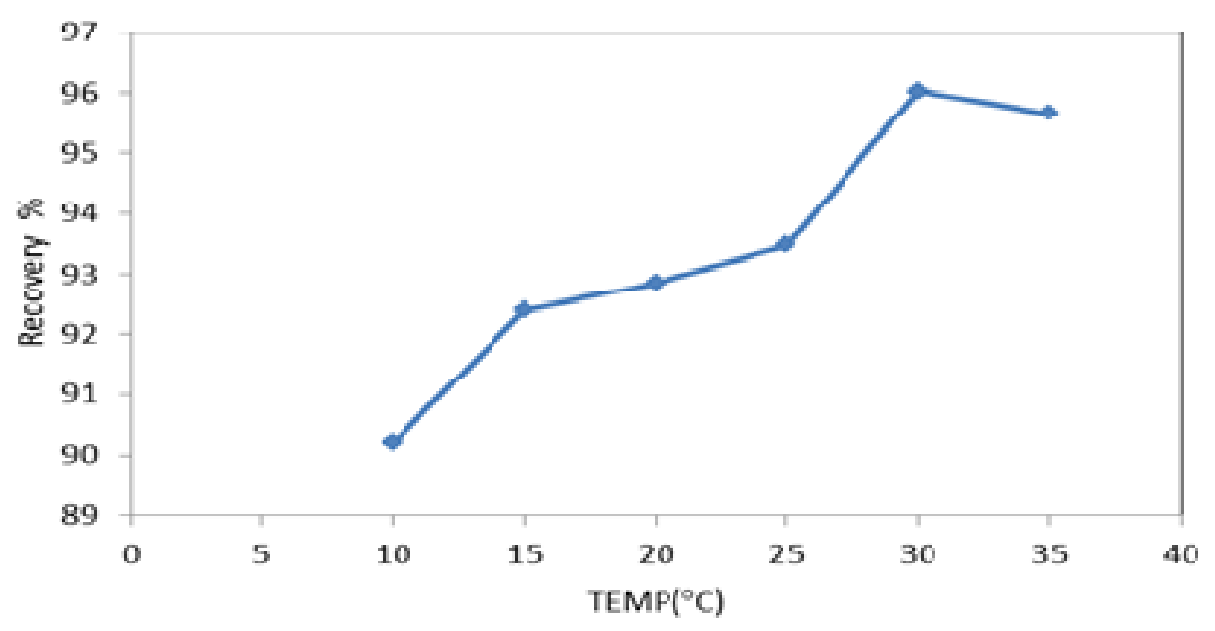

Fig. 8 - Effect of the temperature on the cadmium adsorption efficiency.

Table 1

Investigation of interfering ion at concentration level of $80 \mu \mathrm{g} / \mathrm{L}$ on removal of cadmium ion $1.5 \mathrm{mg} / \mathrm{L}$ APDC as ligand (initial concentration was different ) by $\mathrm{Fe} \mathrm{Mg} \mathrm{Al} \mathrm{LDH}$

\begin{tabular}{|c|c|c|}
\hline Interfering Ion & added $\mathbf{1 . 5} \mathbf{~ m g} / \mathbf{L}\left[\mathbf{C d}^{\mathbf{2}}\right]^{\mathbf{a}}$ & Recvry \% \\
\hline $\mathbf{C r}^{3+}$ & 6.04 & $92.45(2.0)^{\mathbf{a}}$ \\
\hline $\mathrm{Ni}^{2+}$ & 9.73 & $87.83(2.4)$ \\
\hline $\mathrm{Cu}^{2+}$ & 9.81 & $87.73(1.7)$ \\
\hline $\mathrm{Pb}^{2+}$ & 9.73 & $87.83(2.2)$ \\
\hline $\mathrm{Na}^{+}$ & 9.79 & $87.76(2.4)$ \\
\hline $\mathrm{Ca}^{2+}$ & 10.11 & $87.36(2.9)$ \\
\hline $\mathrm{Zn}^{2+}$ & 9.87 & $87.66(1.9)$ \\
\hline $\mathrm{Ag}^{+}$ & 9.84 & $87.7(2.4)$ \\
\hline $\mathrm{K}^{+}$ & 9.76 & $87.8(2.3)$ \\
\hline $\mathrm{Co}^{2+}$ & 9.81 & $87.73(1.3)$ \\
\hline $\mathrm{Al}^{3+}$ & 9.79 & $87.76(2.0)$ \\
\hline
\end{tabular}

${ }^{a}$ Values in parentheses are RSDs based on five individual replicate analysis 


\section{Selected of eluent solvent}

The efficiency of adsorption highly depends on the type of eluent solvent and should be carefully investigated. This process is divided into two main steps. At the first step, the experiment was performed under the optimal values obtained in the previous steps and the adsorbent removed from the sample solution and dried to prepare it for the second step. At the next step different solvents (acetone, ethanol, methanol, acid, acetone-acid, ethanol-acid and methanol-acid) were added to the adsorbent. After that, the adsorbent was separated from the sample solution and the signal of the analyte was measured. The desorption efficiencies were calculated in accordance with equation (3) where $V_{d}$ is the volume of the desorption solvent, $\mathrm{C}_{\mathrm{i}}$ is the remained concentration of cadmium, $\mathrm{V}_{0}$ is the initial volume of the sample solution and $\mathrm{C}_{0}$ is the initial concentration of cadmium. The results showed that acetone had the highest dessorption efficiency (Fig. 9).

$$
R \%=\frac{V_{d} \times C_{i}}{V_{0} \times C_{0}} \times 100
$$

\section{Effect of eluent solvent volume}

Acetone was chosen as the suitable solvent for eluting the cadmium ions from the adsorbent in the previous step as it has the highest efficiency. In this section, after carrying out the procedure under the optimal experimental conditions, different volumes of the acetone were added to the adsorbent. The eluted cadmium ions were analyzed by FAAS and the efficiencies were calculated based on the eq. 3. As shown in Fig. 10, $20 \mathrm{~mL}$ of acetone was enough to achieve satisfactory efficiency.

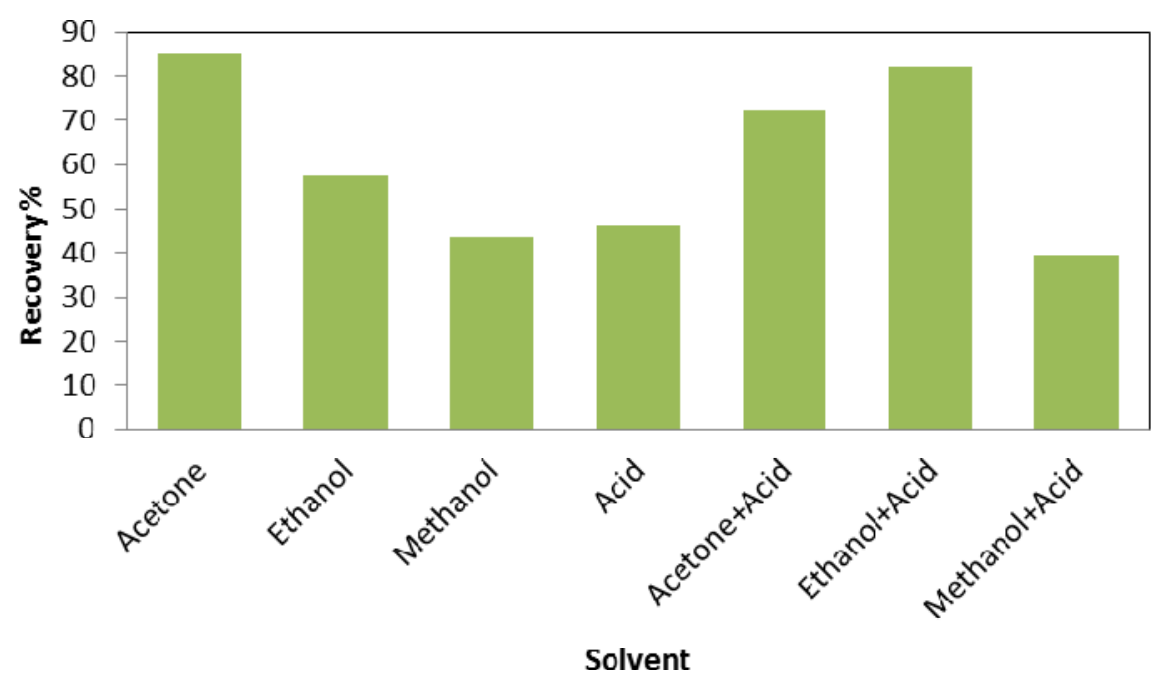

Fig. 9 - Effect of the eluent solvent type on the cadmium removal efficiency.

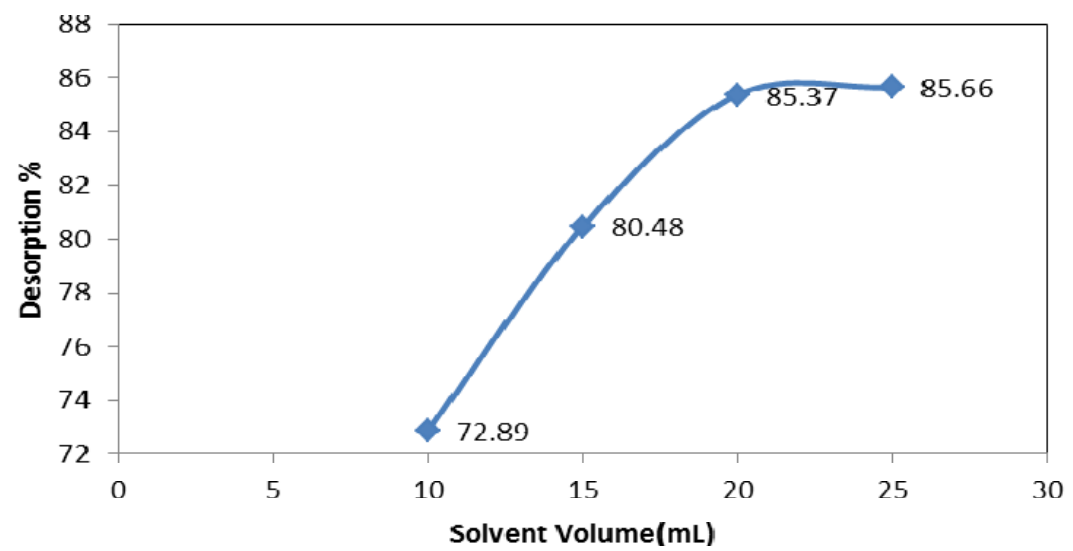

Fig. 10 - Effect of the volume of the acetone on the cadmium removal efficiency. 
Table 2

Recovery of cadmium added to $1000 \mathrm{~mL}$ of different water samples $(\mathrm{pH}=6.5-7.0)$.

\begin{tabular}{lll}
\hline Sample & $\mathbf{C d}^{2+}$ added $(\boldsymbol{\mu g})$ & $\mathbf{C d}^{2+}$ determined $\left(\mathbf{n g} \cdot \mathbf{m L}^{-1}\right)$ \\
\hline Wall water & 0.0 & $1.10(0.9)^{\mathrm{a}}$ \\
& 10.0 & $11.22(1.2)$ \\
Snow water & 0.0 & N.D. \\
& 10.0 & $10.95(1.9)$ \\
Rain water & 0.0 & N.D. \\
& 10.0 & $10.78(0.8)$ \\
Sea Water & 0.0 & $13.57(0.7)$ \\
& 10.0 & $23.98(1.2)$ \\
\hline
\end{tabular}

${ }^{\text {a }}$ Values in parentheses are RSDs based on five individual replicate analysis

${ }^{\mathrm{b}}$ Not Detection

\section{Repeatability}

In order to obtain the RSD of the method, five samples with the same concentrations of ligand and cadmium ions were prepared and the experiments were carried out under optimal experimental conditions for all samples. Based on the obtained results, RSD was at $2.05 \%$.

\section{Real sample analysis}

Solutions with varying densities along with APDC ligand have been prepared by standard addition method. To this aim, Wall water, snow water, rain water Tehran 10 th February 2020 and sea water 20 th February 2020 Caspian sea were passed through the filter and were kept in the containers which have been washed by nitric acid. The solutions were kept at 30 Celsius degree and in $7 \mathrm{pH}$ and for 35 minutes were exposed to 0.045 of absorbent. After the separation process and reading the signals by using the atomic absorption device, the absorption rate and its procedure was investigated. It should be noticed that the samples of drinking water, snow water, rain water and sea water were investigated without absorbent, cadmium, ligand and in normal situation by using the atomic absorption device. The results are shown in Table 2.

\section{Adsorption isotherms}

In order to find the adsorption kinetics of cadmium on the adsorbent, Langmuir, Temkin and Freundlich isotherms were used. The amount of absorbed cadmium ion during equilibrium $\left(\mathrm{q}_{\mathrm{e}}\right.$ $(\mathrm{mg} / \mathrm{g}))$ was calculated by Equation (1). ${ }^{18}$ Adsorption isotherms are equations for describing the equilibrium state of the absorbent between the solid and fluid phases. ${ }^{18}$ The experimental data were further fitted by three equilibrium models, Langmuir (Eq. 4), Temkin (Eq. 5) and Freundlich (Eq. 6) model. ${ }^{19,20}$

$$
\begin{gathered}
\frac{C_{e}}{q_{e}}=\frac{1}{Q_{0} b}+\frac{C_{e}}{Q_{0}} \\
q_{e}=B \ln k_{T}+B \ln C_{e} \\
\log q_{e}=\log K_{f}+\frac{1}{n} \log C_{e}
\end{gathered}
$$

where $\mathrm{C}_{\mathrm{e}}(\mathrm{mg} / \mathrm{L})$ and $\mathrm{q}_{\mathrm{e}}(\mathrm{mg} / \mathrm{g})$ are the equilibrium adsorbate concentration in the aqueous and solid phases, respectively; $\mathrm{Q}_{0}(\mathrm{mg} / \mathrm{g})$ is the maximum adsorption capacity and $b(\mathrm{~L} / \mathrm{mg})$ is the Langmuir adsorption equilibrium constant, $\mathrm{B}$ is the Temkin equilibrium constant, $\mathrm{K}_{\mathrm{T}}$ is the Temkin parameter, $\mathrm{n}$ is the constant of the Freundlich isotherm curvature and $\mathrm{K}_{\mathrm{f}}\left((\mathrm{mg} / \mathrm{g}) /(\mathrm{mg} / \mathrm{L})^{\mathrm{n}}\right)$ is the Freundlich equilibrium constant. The related parameters of the three models along with regression coefficients were summarized in Table 3.

\section{Adsorption thermodynamic}

The thermodynamic equations and parameters provide information about internal energy changes related to sorption process. The thermodynamic parameters show spontaneous or non-spontaneous of processes, endothermic or exothermic of the reactions and the entropy changes during the adsorption process. The thermodynamic parameters are Gibb's free energy $\left(\Delta G^{0}\right)$, standard enthalpy change $\left(\Delta \mathrm{H}^{0}\right)$ and entropy change $\left(\Delta \mathrm{S}^{0}\right)$ which are the most important parameters of an adsorption process in practical applications. 
The standard free energy change $\left(\Delta \mathrm{G}^{0}\right)$ can be calculated from the following equation (Eq. 7):

$$
\Delta G^{0}=-R T \operatorname{Ln} K
$$

where $\mathrm{R}$ is the universal gas constant $(8.314 \mathrm{~J}$ $\mathrm{mol}^{-1} \mathrm{~K}^{-1}$ ), $\mathrm{T}$ is the temperature $(\mathrm{K})$ and $\mathrm{K}$ is the sorption equilibrium constant.

The standard entropy change $\left(\Delta \mathrm{S}^{0}\right)$ can be calculated according to the following equation or by plotting $\operatorname{lnK}$ versus $1 / \mathrm{T}$ $\left(\ln K=\frac{\Delta S^{0}}{R}-\frac{\Delta H^{0}}{R T}\right) \cdot 22-28$

$$
\Delta G^{0}=\Delta H^{0}-T \Delta S^{0}
$$

The obtained thermodynamic data are listed in Table 4. Gibbs free energy change $\left(\Delta G^{0}\right)$ for all of the studied temperatures was negative suggesting that the adsorption of $\mathrm{Cd}$ ions onto Fe@Mg-Al LDH was thermodynamically feasible and spontaneous. Since the $\Delta \mathrm{G}^{0}$ values are between 0 and -20 , it can be said that the mechanism of absorption is a physical sorption. The negative value of $\Delta \mathrm{H}^{0}$ indicates that the sorption of cadmium ions on $\mathrm{Fe} @ \mathrm{Mg}-\mathrm{Al} \quad \mathrm{LDH}$ is an endothermic process in nature. The negative value of the entropy change $\left(\Delta S^{0}\right)$ suggests that the degree of freedom is reduced at the solid-solution interface during the sorption of $\mathrm{Cd}^{2+}$ from the sample solution.

\section{Magnetic nanoparticles of Fe@Mg-Al LDH efficiency}

Undoubtedly, one of the major parameters affecting in the removal is the efficiency of the used membrane Magnetic nanoparticles of Fe@Mg-Al LDH. However, to the best of our knowledge this case has not been discussed elsewhere in similar reports. Under the optimum experimental conditions, it was found out that each Magnetic nanoparticles of Fe@Mg-Al LDH could perform at least 14 replicate analyses if organic eluting solvents are used. On the other hand, acidic, eluents practically decrease the number of time a Magnetic nanoparticles of Fe@Mg-Al LDH could be used to 10 replicates. These observations are represented in Fig. 11.

Table 3

Langmuir, Temkin and Freundlich isotherms constants for the adsorption of cadmium (II) ion by Fe@ Mg Al LDH

\begin{tabular}{|ccccccccc}
\hline & Langmuir Isotherm & \multicolumn{3}{c}{ Temkin Isotherm } & \multicolumn{3}{c}{ Freundlich Isotherm } \\
\hline $\mathbf{Q}_{\mathbf{0}}$ & $\mathbf{b}$ & $\mathbf{R}^{\mathbf{2}}$ & $\mathbf{a}_{\mathbf{t}}$ & $\mathbf{B}_{\mathbf{0}}$ & $\mathbf{R}^{2}$ & $\mathbf{n}$ & $\mathbf{K}_{\mathbf{f}}$ & $\mathbf{R}^{2}$ \\
54.6 & 3.514 & 0.976 & 41.88 & 11.942 & 0.7921 & 1.42 & 67.43 & 0.9459 \\
\hline
\end{tabular}

Table 4

Thermodynamics Parameters

\begin{tabular}{|c|c|c|c|c|}
\hline $\mathbf{T}\left(\mathbf{K}^{\mathbf{0}}\right)$ & $\mathbf{L n K}$ & $\left.\Delta \mathbf{G}^{\mathbf{0}} \mathbf{( K J} / \mathbf{m o l}\right)$ & $\Delta \mathbf{H}^{\mathbf{0}}(\mathbf{K J} / \mathbf{m o l})$ & $\Delta \mathbf{S}^{\mathbf{0}}(\mathbf{K J} / \mathbf{m o l} . \mathbf{K})$ \\
\hline 283 & 2.04 & -4.79 & -46.674 & -0.148 \\
\hline 293 & 1.36 & -3.31 & & \\
\hline 293 & 0.63 & -1.58 & & \\
\hline
\end{tabular}

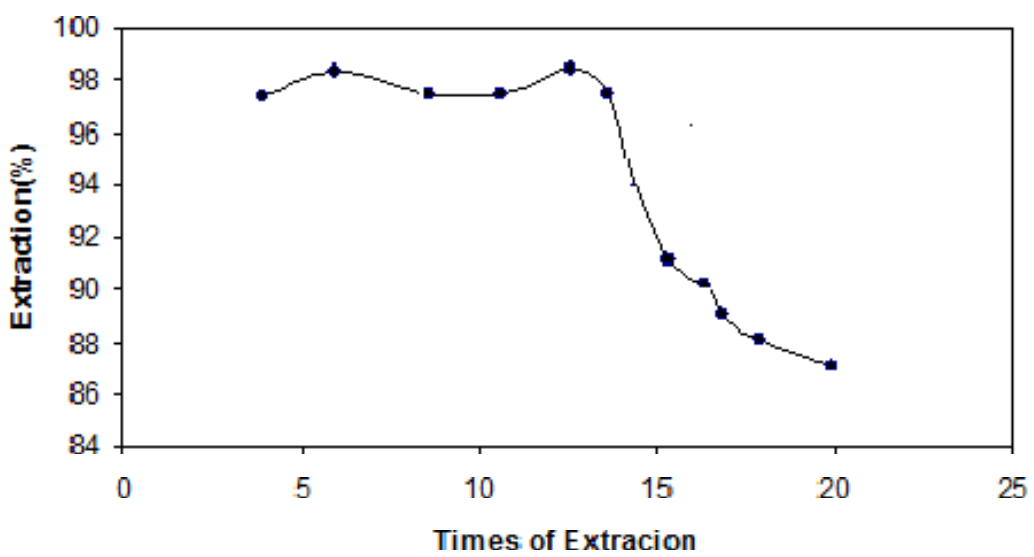

Fig. 11 - Influence of eluent (20 mL of acetone) type on Magnetic nanoparticles of Fe@Mg-Al LDH efficiency. 
Table 5

Characteristic performance data obtained by using magnetic nanoparticles of Fe@Mg-Al layered double hydroxide have been modified with ammonium pyrrolidine dithiocarbamate (APDC)and other techniques in determination of $\mathrm{Cd}^{2+}$ in water sample

\begin{tabular}{|c|c|c|c|c|}
\hline References & Recovery\% & $\begin{array}{l}\text { Time } \\
(\min )\end{array}$ & $\begin{array}{c}\text { R.S.D. } \\
\text { (\%) }\end{array}$ & Method \\
\hline [8] & $85 \%$ & $>10$ & 7.4 & SDME-GF AAS CPE-GF AAS \\
\hline [10] & $89 \%$ & $>30$ & 2.1 & Cloud Point Extraction \\
\hline [29] & $90 \%$ & $>16$ & 3.2 & chitosan derivative for the removal of $\mathrm{Cd}^{2}$ magnetic \\
\hline $\begin{array}{l}\text { [Represented } \\
\text { method] }\end{array}$ & $88 \%$ & $<4$ & 2.05 & $\begin{array}{c}\text { nanoparticles of Fe@Mg-Al layered double } \\
\text { hydroxide-F AAS }\end{array}$ \\
\hline
\end{tabular}

${ }^{\mathrm{a}}$ Limit of detection

${ }^{\mathrm{b}}$ Relative standard deviation

In this research, Fe@Mg-Al LDH nanocomposite was used for removing the cadmium ions from the solution. It should be noted that it is used for the first time, because in article 1 it was extracted by using the following absorbent 1. Nephtol and 2. Nephtol by using MPSE). For the comparison, Sankararamakrishnan and his co-workers used Chemical Chitosan for dropping the Cadmium from pops, in which they investigated the effective parameters like the absorption time, amount of absorption and $\mathrm{pH}$ and the results were 16 hours, $5 \mathrm{~g} / \mathrm{L}$ and 8 respectively. ${ }^{29}$

\section{CONCLUSION}

The primary and main target of this research is to provide a simple, effective, reproducible and inexpensive method to remove heavy metal ions. The impact of various effective factors on the absorption of $\mathrm{Cd}^{2+}$ was investigated. Optimum conditions for adsorption of Cadmium was $\mathrm{pH} 7$, contact time of 35 min, adsorbent amount of $0.045 \mathrm{~g}, 1.7 \mathrm{mg} \mathrm{L}^{-1}$ of APDC ligand, $25 \mathrm{~mL}$ of the sample solution, the temperature of $30 \mathrm{C}^{\circ}, 20 \mathrm{~mL}$ of eluent solvent (acetone). The adsorbent had a satisfactory recovery in the presence of interfering ions. In addition, acceptable efficiencies were achieved to detect cadmium in drinking water samples. The adsorption of cadmium was spontaneous and the randomness was decreased at the solid-solution interface during the sorption process.

Acknowledgments. This study was supported by Islamic Azad University of Varamin.

\section{REFERENCES}

1. Q. Zhou, M. Lei, J. Li, K. Zhao and Y. Liu, J. chromatography A, 2016, 1441, 1-7.

2. K. B. Zumreoglu and A. Ay, Chem. Pap., 2012, 66, 1-100.
3. K. Goh, T. Lim A. Banas and Z. Dang, , Water Res., 2008, 42, 1343-1368.

4. A. Jawad, Z. Chen, Z. Liao, Z. Zhou, Z. Chen, A. Khan, T. Wang, J. Ifthikar, A. Shahzad, Z. Chen and Z. Chen, $A C S$ Appl. Mater. Interfaces, 2017, 9, 34-40.

5. S. Yu, Y. Liu, Y. Ai, X. Wang, R. Zhang, Z. Chen, Z .Chen, G. Zhao and X. Wang, Environ. Pollut., 2018, 242, 1-11.

6. Z. Li, X. Chang, X. Zou, X. Zhu, Z. Nie. Z. Hu and R. Li, Anal. Chem. Acta., 2009, 632, 272-276.

7. J. D. Kinrade and J. C. Vanloon, Anal. Chem., 1974, 46, 1894-1899.

8. Z. Fan and W. Zhou, Spectrochim. Acta Part B, 2006, 61, 870-874.

9. M. Abniki, A. Moghimi, F. Azizinejad, J. Serb. Chem. Soc., 2020, 84, 1-13.

10. X. Zhu, X. Zhu and B. Wang, Microchim. Acta, 2006, 154, 95-100.

11. S. Civband, P. Shirazi, L. Divband, S. Azadi and P. Tishehzan, J. Water Sus. Dev., 2014, 1, 35-41.

12. I. López-García, Y. Vicente-Martínez and M. HernándezCórdoba, J. Anal. At. Spectrom, 2015, 30, 375-380.

13. S. Dadfarnia, M. Talebi, A. M. Haji Shabani and Z. Amani Beni, Crotica. Chem. Acta., 2017, 80, 17-23.

14. N. Sakalar, M. H. Bilir, B. Acemioglu and M. H. Alma, Asian. J. Chem., 2010, 22, 5649-5662.

15. O. Abdelwaheb, Egypt. J. Aquat. Res., 2007, 33, 125-143.

16. H. Chen, J. Han, Y. Wang, Y. Hu, L. Ni, Y. Liu, W. Kang and Y. Liu, Micrchem. Acta, 2014, 181, 1455-1461.

17. M. Moradi, R. Kashanaki, S. Borhani, H. Bigdeli, N. Abassi and A. Kazemzadeh, J. Mol. Liq., 2017, 232, 243-250.

18. A. Gill, F. C. C. Assis, S. Albeniz and S. A. Korili, J. Chem. Eng., 2011, 168, 1332-1340.

19. N. Cancer, I. Kiran, S. Ilhan and C. F. Iscen, J. Hazard. Mater., 2009, 165, 279-284.

20. M. Siddique, R. Farooq, A. Khalid, Q. Mahmood and U. Farooq, J. Hazard. Mater., 2009, 172, 1007-1012.

21. M. J. Jaycook and G. D. Parfitt, "Chemistry of interfaces", Ellis Horwood Ltd, Onichester, 1981, p. 12-13.

22. S. Saravanan and L. Ravikumar, J. Water Resour. Prot., 2015, 7, 530-545.

23. Z. M. Abou-Gamra and M. A. Ahmed, ACES, 2015, 5, 373388.

24. A. Moghimi, Russ. J. Phys. Chem. A, 2013, 87, 1851-1858.

25. A. Moghimi, J. Chem. Health Risks, 2014, 4, 15-22.

26. A. Moghimi, Chin. J. Chem., 2007, 25, 640-648.

27. A. Moghimi, Chin. J. Chem., 2007, 25, 1536-1541.

28. A. Moghimi, Russ. J. Phys. Chem. A, 2013, 87, 1203-1209.

29. N. Sankararamakrishnan, A. Kumar Sharma and R. Sanghi, J. Hazard. Mater., 2007, 148, 353-359. 
